\title{
Global incidence and outcome of testicular cancer
}

This article was published in the following Dove Press journal:

Clinical Epidemiology

16 October 2013

Number of times this article has been viewed

Thurkaa Shanmugalingam'

Aspasia Soultati

Simon Chowdhury ${ }^{2}$

Sarah Rudman ${ }^{2}$

Mieke Van Hemelrijck'

'King's College London, School of Medicine, Division of Cancer Studies, Cancer Epidemiology Group, London, UK; ${ }^{2}$ Department of Oncology, Guy's and St Thomas' NHS Foundation Trust, London, UK
Correspondence: Mieke Van Hemelrijck King's College London, School of Medicine, Division of Cancer Studies, Cancer Epidemiology Group, 3rd Floor, Bermondsey Wing, Guy's Hospital, London, SEI 9RT, UK

Tel +44 2071887904

Email mieke.vanhemelrijck@kcl.ac.uk
Background: Testicular cancer is a rare tumor type accounting for $1 \%$ of malignancies in men. It is, however, the most common cancer in young men in Western populations. The incidence of testicular cancer is increasing globally, although a decline in mortality rates has been reported in Western countries. It is important to identify whether the variations in trends observed between populations are linked to genetic or environmental factors.

Methods: Age-standardized incidence rates and age-standardized mortality rates for testicular cancer were obtained for men of all ages in ten countries from the Americas, Asia, Europe, and Oceania using the Cancer Incidence in Five Continents (CI5plus) and World Health Organization (WHO) mortality databases. The annual percent change was calculated using Joinpoint regression to assess temporal changes between geographical regions.

Results: Testicular cancer age-standardized incidence rates are highest in New Zealand (7.8), UK (6.3), Australia (6.1), Sweden (5.6), USA (5.2), Poland (4.9), and Spain (3.8) per 100,000 men. India, China, and Colombia had the lowest incidence ( $0.5,1.3$, and 2.2 , respectively) per 100,000 men. The annual percent changes for overall testicular cancer incidence significantly increased in the European countries Sweden 2.4\%, (2.2; 2.6); UK 2.9\%, (2.2; 3.6); and Spain 5.0\%, (1.7; 8.4), Australia 3.0\%, $(2.2 ; 3.7)$, and China $3.5 \%,(1.9 ; 5.1)$. India had the lowest overall testicular cancer incidence $-1.7 \%$, $(-2.5 ;-0.8)$. Annual percent changes for overall testicular cancer mortality rates were decreasing in all study populations, with the greatest decline observed in Sweden $-4.2 \%,(-4.8 ;-3.6)$ and China $-4.9 \%,(-6.5 ;-3.3)$.

Conclusion: Testicular cancer is increasing in incidence in many countries; however, mortality rates remain low and most men are cured. An understanding of the risks and long-term side effects of treatment are important in managing men with this disease.

Keywords: testicular cancer, global, incidence, mortality

\section{Introduction}

Testicular cancer is a relatively rare tumor type accounting for approximately $1 \%$ of all male cancers globally. ${ }^{1}$ However, testicular cancer has a very distinctive age distribution and in many developed countries it is the most commonly diagnosed malignancy among men aged between 15-40 years. ${ }^{2}$ In recent decades, the incidence of testicular cancer has been increasing, with a doubling observed since the 1960s in many Western societies. Both Western and Northern Europe have high age-standardized incidence rates of 7.8 and 6.7 per 100,000 men, respectively, compared to rates of 0.6 per 100,000 men in the black population of Northern Africa. ${ }^{3}$ However, despite these observed trends in incidence and geographical variations, few hypotheses exist to explain them. ${ }^{4}$ 
Since testicular cancer peaks in incidence among young men of reproductive age, it is believed that high estrogen levels in utero may contribute to the development of testicular cancer. ${ }^{5}$ The majority ( $98 \%$ ) of testicular tumors are of germ-cell origin, although testicular abnormalities such as cryptorchidism are a known risk factor for testicular cancer. This may suggest a combination of genetic and environmental factors is important in its etiology.

The increasing trends in global testicular cancer incidences have been linked to a strong birth cohort effect; this suggests that an individual's risk is primarily a result of the era in which he was born. ${ }^{6}$ For example, a study in Norway noticed that males born in the 5-year interval during the Nazi occupation (1940-1944) had a lower incidence rate compared to males born before the occupation (1935-1939). It is thought that this observed effect can be explained by environmental exposures including dietary changes and a fall in use of polluting vehicles during that time. ${ }^{7}$

In contrast to incidence, there has been a remarkable decline in testicular cancer mortality in European countries over the past 30 years. This has been attributed to the introduction of platinum-based chemotherapy regimens and guidelines to help standardize tumor management. Untreated testicular cancer may metastasize and eventually lead to death, but advances in treatment have resulted in increases in 5-year survival rates from $63 \%$ to more than $90 \%$ during the last 3 decades. ${ }^{8}$ Accordingly, a pooled 5-year relative survival of greater than $90 \%$ was reported in the 1990s EUROCARE (EUROpean CAncer REgistry) for European testicular cancer patients, except for Slovenia and Estonia, where there was a significantly lower survival rate. ${ }^{9}$ Given that investigations into global trends in incidence and mortality of testicular cancer have generally focused on populations of European descent, it is unclear whether low-incidence populations also show an increase over time and whether the decline in mortality is still observed. This paper aims to investigate the changes in temporal patterns in global incidence and mortality rates of testicular cancer, using the Cancer Incidence in Five Continents (CI5plus) and the World Health Organization (WHO) mortality database from ten populations in the Americas, Asia, Europe, and Oceania. ${ }^{3,10,11}$ Any temporal changes in testicular cancer mortality rates may reflect the quality of health care provided across different geographical regions, in particular the introduction of multidisciplinary specialist care. Since more and more men are being diagnosed with testicular cancer, the second aim of the paper explores our understanding of this disease in relation to the variation in incidence and mortality of testicular cancer between geographic regions.
In particular, the risk factors leading to familial and sporadic testicular cancer in migrating populations, the differences that are attributable to emerging new prognostic factors, and the consequences of late treatment effects.

\section{Materials and methods Literature review}

We used a computerized literature search database (PubMed) to identify full text and abstract studies publishing the global incidence and outcome of testicular cancer to date. For the first aim of the paper, searches were conducted with the terms "germ cell tumor", "epidemiology", "incidences", "mortality", and "global/worldwide" between 1990 to 2012. Search terms for the second aim of the paper included "risk factors", "treatment", "late effects", and "prognosis" from 1990 to 2012. Except for limiting searches to the English language, human subjects, and adults, no additional restrictions were added to the search.

\section{Data collection}

Average annual incidence rates of testicular cancer (International Classification of Diseases, Revision 10 [ICD-10] code C62) were selected from population-based registries for men of all ages, within the CI5plus database. Average annual mortality rates of testicular cancer (ICD-10 code C62) were selected from population-based registries for men of all ages, within the WHO mortality database. These values reflect the estimated annual rate of cancer incidence and mortality per 100,000 men. The CI5plus and WHO mortality databases are projects engineered by the International Agency for Research on Cancer (IARC), a subdivision of WHO. ${ }^{10,11}$

Populations were chosen for inclusion in our analysis on the basis of one major criterion - only one registry from each country was chosen for trend analysis. If more than one registry met the basic criteria, the registry with the largest population was included. In order to display incidence and mortality rates from as wide a geographic range as possible, registries were selected by ensuring that within a time period all years had data on age-standardized rate; this was done in order to calculate annual percent change. A total of ten populations were chosen: two from the Americas (USA [Surveillance Epidemiology and End Results (SEER) for incidence rates, a total of nine registries] and Columbia [city of Cali for incidence rates]), two from Asia (India [Mumbai, however, no data on mortality were available on the WHO database for India], and China, [Hong Kong]), four from Europe (UK [England for incidence rates, a total of five registries and England and Wales for mortality 
rates], Sweden, Spain [city of Zaragoza for incidence rates] and Poland [Warsaw city for incidence rates]), and two from Oceania (Australia [city of New South Wales for incidence rates] and New Zealand). No African population met the inclusion criteria, since there were no available cancer registries in the databases. The WHO mortality database had several registries missing for several years for Poland and the USA.

\section{Data analysis}

The annual testicular cancer incidence and mortality trends were investigated by calculating the annual percent changes in disease rates. The annual percent changes were estimated with log-linear Poisson regression models, using the US National Cancer Institute's Joinpoint Regression Analysis Program (Version 3.5.4). ${ }^{12}$ The remaining analysis was performed using Microsoft Excel (Microsoft Corporation, Redmond, WA, USA).

\section{Results}

Figure 1A shows the global annual age-standardized incidence rate from 1958-2002 where the developed countries analyzed demonstrated a greater annual increase in testicular cancer incidence compared to the developing countries studied (1980-2002). Figure 1B shows the global annual age-standardized mortality rate from 1955-2010 for testicular cancer. A decline in mortality is observed in all regions, although this is more pronounced among the European and Oceanic countries. A comparison of overall annual percent change for testicular cancer incidence and mortality rates for each country is described in Figure 1C. An increase in incidence is seen in all areas studied, whilst a decrease in mortality is observed in all regions except Colombia and Poland.

\section{Incidence}

The annual age-standardized incidence rates for testicular cancer in the Swedish population from 1958-2002 are shown in Figure 2A. The testicular cancer incidence has steadily risen since 1975, peaking in 2002 at 5.6 per 100,000 men. The annual percent change for testicular cancer incidence (Table 1) also showed a significant overall annual increase of $2.4 \%$ (1958-2002). Figure 2B shows the annual agestandardized incidence rate of testicular cancer for the population living in England between 1985 and 2002. Incidence data available from the mid-1980s demonstrates an overall increase in incidence particularly from the mid-1990s. The annual percent change for overall testicular cancer incidence rates significantly increased annually (2.9\%) between 1985 and 2002; the increase is surprisingly greater than what was
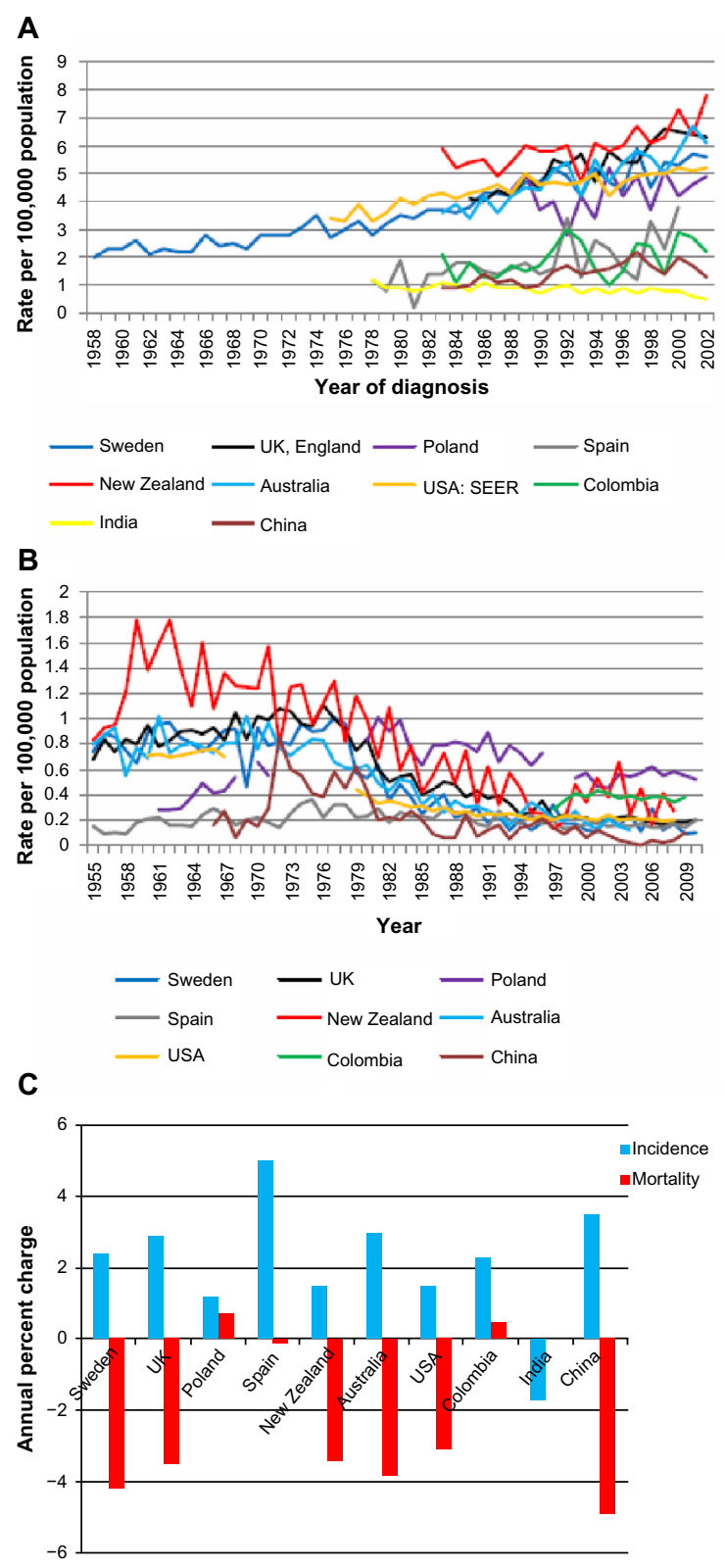

Figure I Global annual age-standardized incidence and mortality rates (per I00,000 men) for testicular cancer by year and overall annual percent changes for ten countries. Notes: (A) Global annual age-standardized incidence rates (per 100,000) for testicular cancer by year: Sweden (1958-2002), UK (1985-2002), Poland (1988-2002), Spain (1978-2000), New Zealand (1983-2002), Australia (1983-2002), USA (1975-2002), Colombia (1983-2002), India (1978-2002), and China (1983-2002). (B) Global annual age-standardized mortality rates (per 100,000) for testicular cancer by year: Sweden (1955-2010), UK (1955-2010), Poland (196I-2010), Spain (1955-2010), New Zealand (1955-2008), Australia (1955-2006), USA (1960-2008), Colombia (1997-2009), and China (1966-2009). (C) Overall annual percent changes for testicular cancer incidence and mortality rates across ten countries.

previously reported, surpassing Sweden (Table 1). The annual testicular cancer age-standardized incidence rate shown in Figure $2 \mathrm{C}$ for the Polish population includes data available from 1988-2002. Unlike other European countries studied, no overall significant increase in testicular cancer incidence 
A

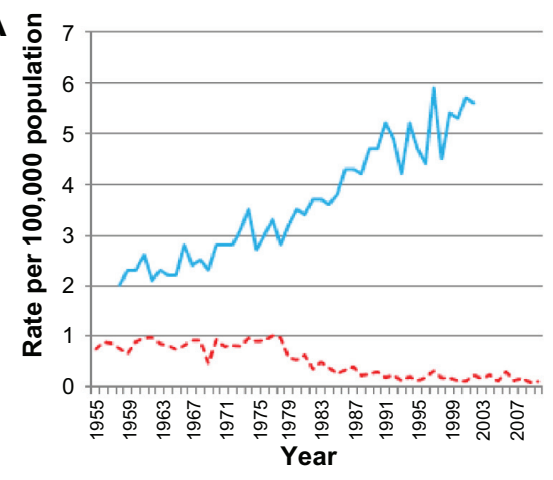

$c$

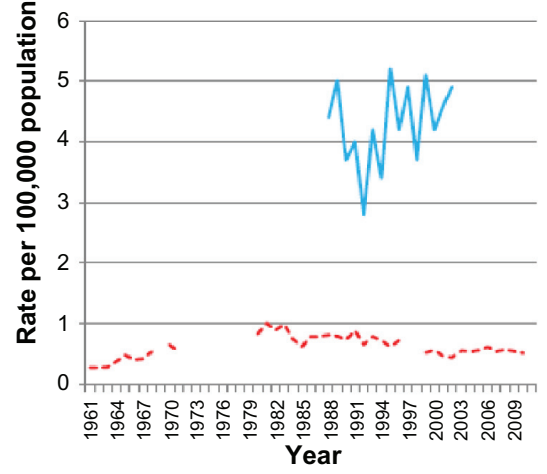

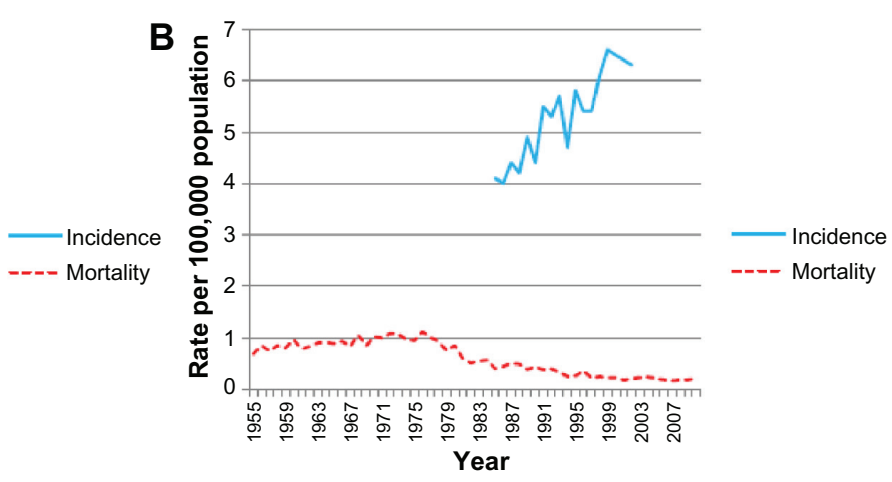
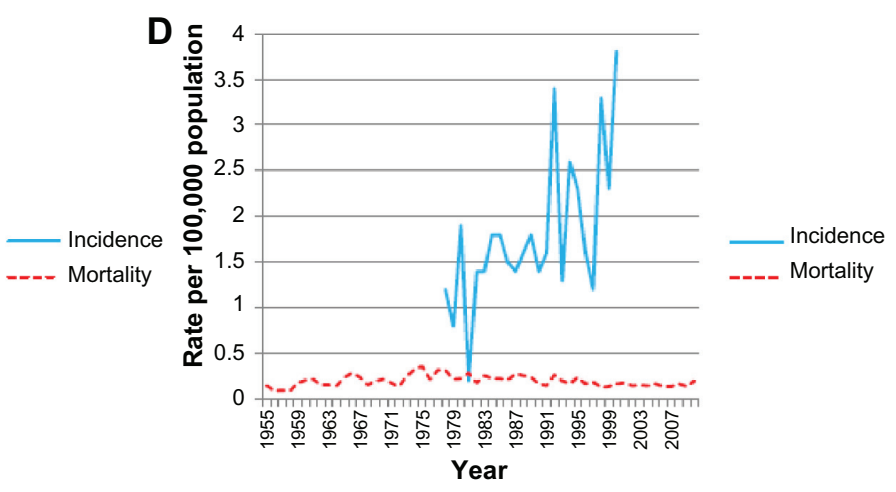

Figure 2 Annual age-standardized incidence and mortality rates (per 100,000) for testicular cancer by year.

Notes: Annual age-standardized incidence and mortality rates (per 100,000) for testicular cancer by year for (A) Sweden (1955-2010), (B) UK (I955-20I0), (C) Poland (196I-2010), and (D) Spain (1955-2010).

is observed, although significant fluctuation in incidence is demonstrated. This distribution is also shown in the testicular cancer incidence rates by annual percent change. An overall non-significant annual increase of $1.2 \%$ during the study period is observed; however this includes an initial large decrease of $-10.1 \%$ (1988-1992) followed by a consecutive increase of 14.1\% (1992-1995) (Table 1). Annual agestandardized incidence rate data was available for the Spanish population from 1978-2000 (Figure 2D). An overall increase in incidence is demonstrated with rates increasing from 1.2 to 3.8 per 100,000 men, although significant fluctuation in values at individual time points was observed. The annual percent change of overall annual incidence rates for testicular cancer increased by $5.0 \%$, unexpectedly exceeding the rise observed in both Sweden and the UK. However, throughout the time periods studied (1978-2000) the annual percent change, like Poland, undergoes significant variation (Table 1). Figure 3A shows the annual age-standardized incidence rate for New Zealand from 1983-2002, with an increase from 5.9 to 7.8 per 100,000 men observed. The corresponding annual percent change for testicular cancer incidence showed a significant overall annual increase of 1.5\% (1983-2002) (Table 1). The annual age-standardized incidence rate for testicular cancer in the Australian population increased from 3.6 to 6.1 from 1983-2002 (Figure 3B). The annual percent change for overall testicular cancer incidence rates significantly increased annually (3.0\%) between 1983 and 2002 (Table 1). The annual testicular age-standardized incidence rate for USA from 1975-2002 is described in Figure 3C. The testicular cancer incidence rates increased over time from 3.4 to 5.2 per 100,000 men. This was associated with a significant overall annual percent change of 1.5\% (1975-2002) (Table 1). The annual testicular cancer age-standardized incidence rate for Colombia varied significantly during the time period studied (1983-2002) with fluctuations in incidence observed from 1 to 3 per 100,000 men. This was mirrored in the changes in annual percent change (29.1\% [1989-1992] and 10.8\% [1995-2002]) although these were not significant (Figure 3D). Overall, an annual increase in incidence rates of 2.3\% was observed (1983-2002) (Table 1).

The annual testicular cancer age-standardized incidence rate for India from 1978-2002 is described in Figure 1. From the ten populations studied, India is the only country that shows a declining trend in testicular cancer incidence rates over time. In addition, the overall annual percent change for incidence fell by $1.7 \%$ (1978-2002), although this was not significant (Table 1). The annual testicular cancer age-standardized incidence rate for China (Hong Kong) is described in Figure 4. The testicular cancer incidence increased over the 20 years from 1983 to 2002 from 0.9 to 1.3 , respectively. This was 


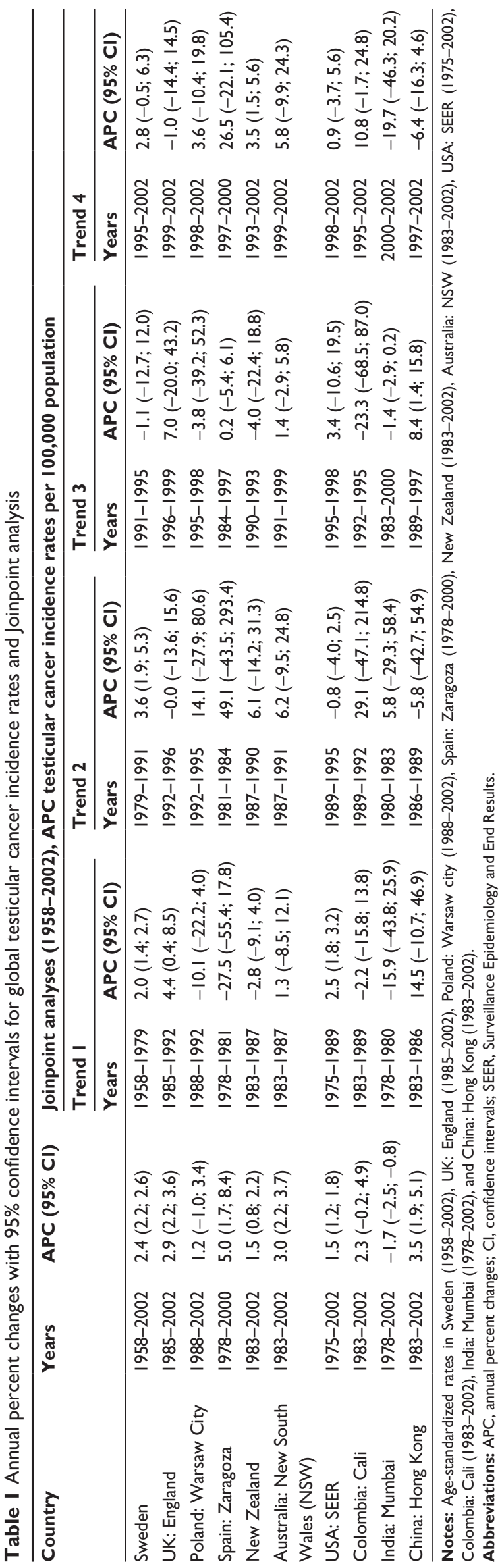

associated with an overall annual rise of 3.5\% (1983-2002) (Table 1). This increase was similar to that observed in the UK and Sweden.

\section{Mortality}

The annual age-standardized mortality rates for testicular cancer in the Swedish population from 1955 to 2010 are described in Figure 2A. These began to decline at the beginning of the $1980 \mathrm{~s}$, then started stabilizing from the early 1990s onwards. This trend was also reflected in the annual percent change, with testicular cancer deaths rates decreasing significantly overall at the rate of $4.2 \%$ annually (1955-2010) (Table 2). Figure 2B shows the annual age-standardized mortality rate of testicular cancer for men living in the UK between 1955 and 2010. These decreased during this time period in a similar distribution to the Swedish population; however, the observable decline occurred earlier, from the mid-1970s onwards. This observation is also reflected in the annual percent change, with annual death rates in the UK declining (3.5\%) over time (1955-2010), with the greatest decrease observed from the mid-1970s (1976-1982) of $9.7 \%$ (Table 2). Mortality data was available for Poland from 1961-2010; however, data points were missing for some years. Although, the annual age-standardized mortality rate for testicular cancer remains low across the time period studied, a slight increase was observed during the 1970s, with an overall slight increase by 2009 (Figure 2C). The annual percent change observed reflected this, with a significant yet small overall increase $(0.7 \%)$. Further analysis of the trends within this period showed significant variation in annual percent change ranging from 14.3\% between 1961 and 1965 to 4.9\% between 1965 and 1981 (Table 2). However, the annual age-standardized mortality rate for the Spanish population was consistently low between 1955 and 2010 (Figure 2D), with a small non-significant annual percent change $(0.1 \%)$.

The annual age-standardized mortality rate for New Zealand declined steadily throughout the time period studied (1955-2008) (Figure 3A). In contrast, testicular cancer deaths rates were decreasing significantly overall at the rate of 3.4\% annually (1955-2008) in a similar trend to the UK and Sweden (Table 2). The annual age-standardized mortality rate for testicular cancer in the Australian population from 1955-2006 resembled the distribution seen for New Zealand with a steady decline in mortality observed from 1970s (Figure 3B); this was associated with an annual percent change of $-3.8 \%$ over time (1955-2006) (Table 2). The annual testicular cancer age-standardized mortality rate for the USA from 1960-2008 is described in Figure 3C. Age-standardized mortality rate data was not 

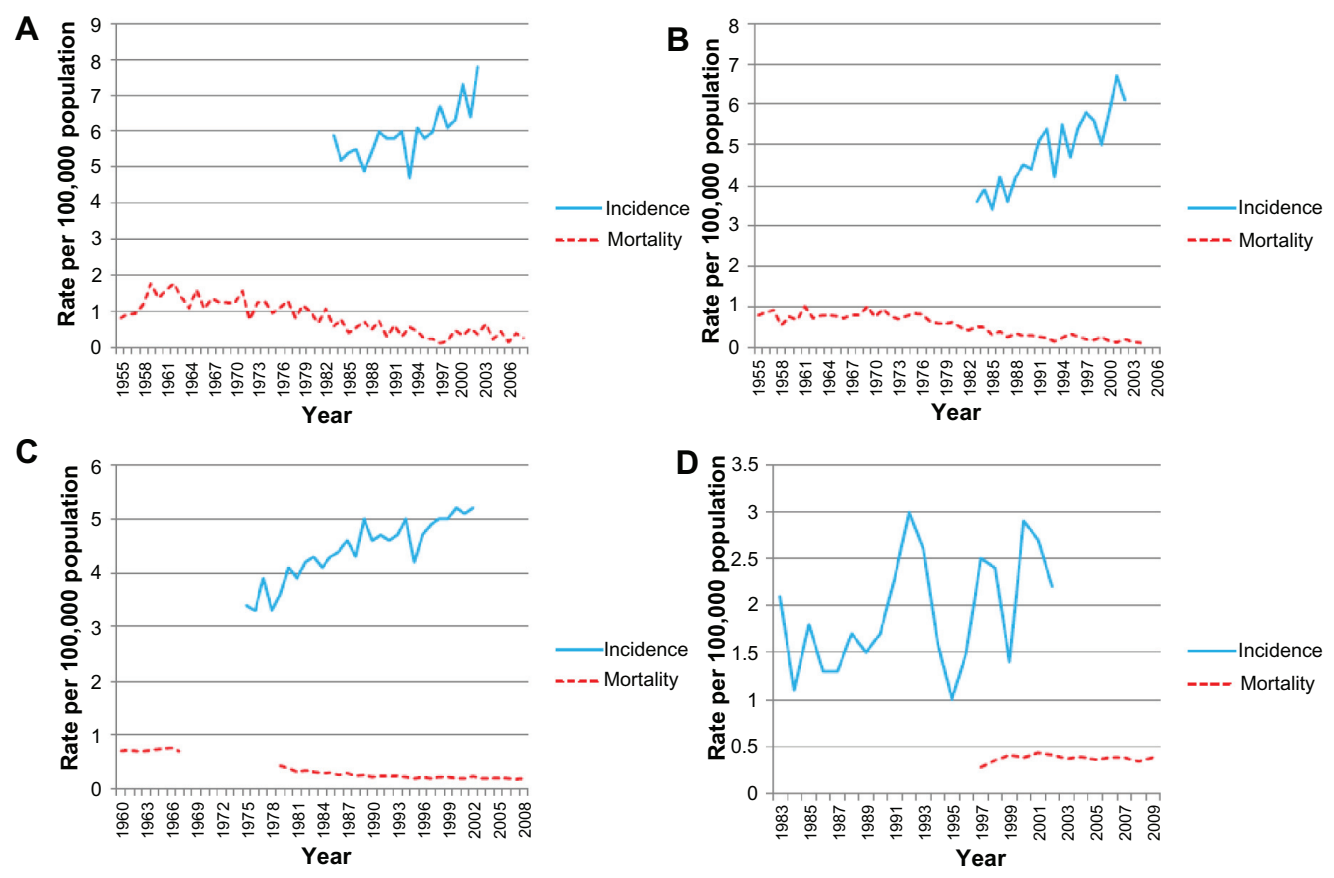

Figure 3 Annual age-standardized incidence and mortality rates (per 100,000) for testicular cancer by year.

Notes: Annual age-standardized incidence and mortality rates (per 100,000) for testicular cancer by year for (A) New Zealand (1955-2008), (B) Australia (1955-2006), (C) USA (1960-2008), and (D) Colombia (1983-2009).

available for the time period from 1968-1978; however, a decline in mortality was observed from 1979 onwards. In addition, an annual overall decrease of $3.1 \%$ was observed between 1960 and 2008 (Table 2). The annual testicular cancer age-standardized mortality rate for Colombia did not change significantly from 1997-2009 (Figure 3D). This was associated with an overall annual percent change of $0.5 \%$ (Table 2 ).
The annual testicular cancer age-standardized mortality rate for China (Hong Kong) from 1966-2009 is described in Figure 4. The age-standardized mortality rate increased during the $1970 \mathrm{~s}$, with a subsequent decrease to 0.1 per 100,000 men by 2009 . The testicular cancer death rates showed an annual decrease overall of 4.9\% (1966-2009); the decline is noticeably larger than European and Oceanic countries (Table 2).

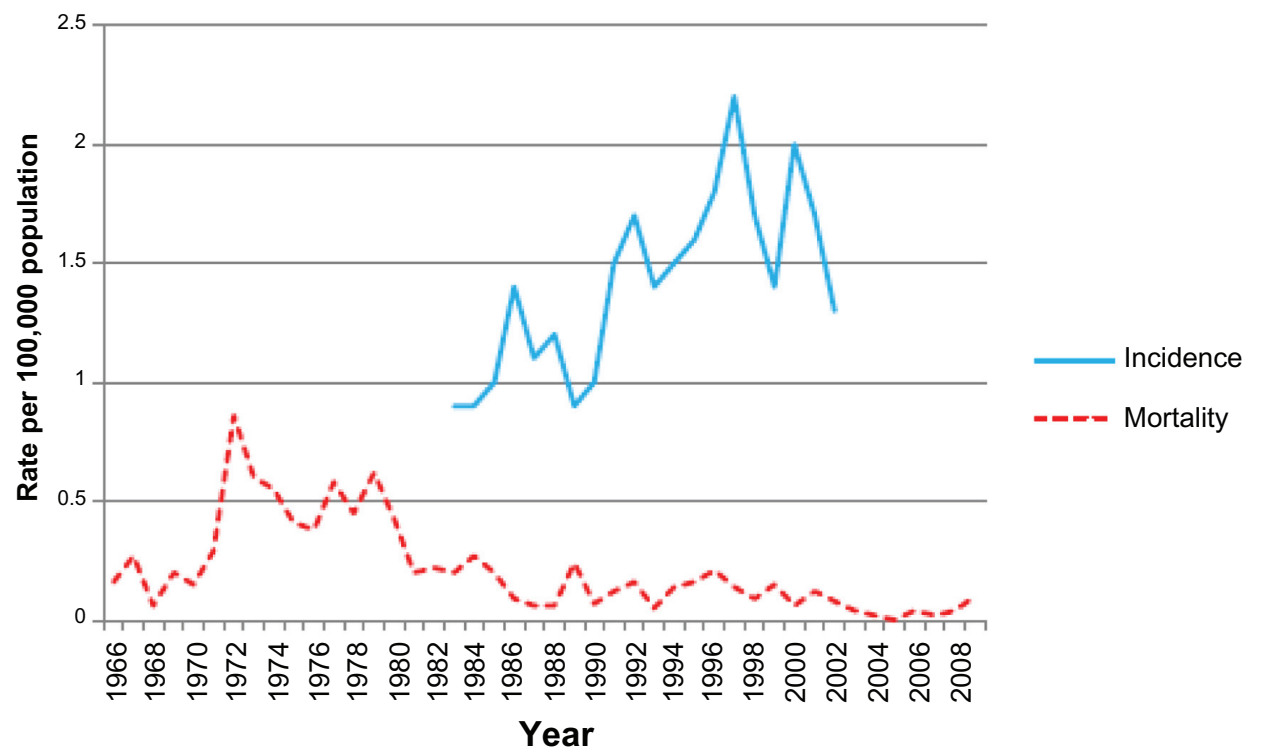

Figure 4 Annual age-standardized incidence and mortality rates (per 100,000) for testicular cancer by year for China (Hong Kong) (1966-2009). 


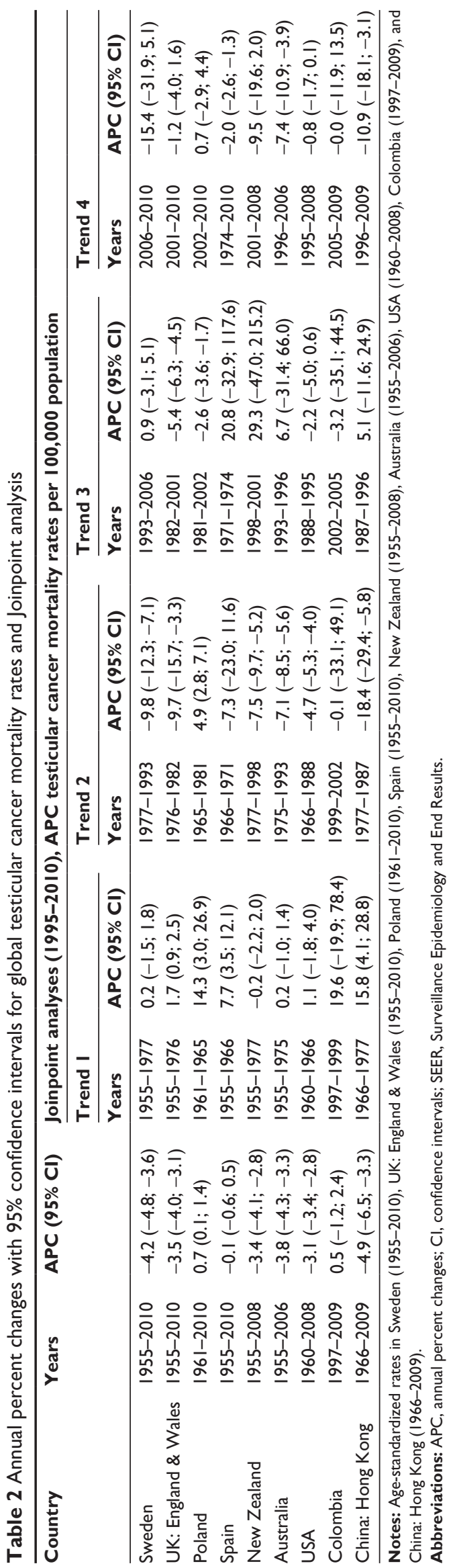

\section{Discussion}

This study describes the recent global patterns of testicular cancer incidence and mortality. Our analyses confirm previous observations that large discrepancies exist in the geographical, ethnic, and temporal patterns of testicular cancer outcomes among the ten selected populations. These wide variations indicate that testicular cancer largely remains a disease primarily of men of Caucasian origin, in particular European- and Oceanic-descended populations. In addition, the decline in mortality rates which commenced as early as the mid-1970s demonstrates improvements in systemic treatment, most notably cisplatin-based combination chemotherapy.

In our study countries were chosen to represent specific global regions and were selected on the basis of the largest and best quality registry data available. In some cases such as the USA and Poland data were not complete, although in Poland's case this represented the best quality and most complete data available for the Eastern European region. No data were available for this analysis from African countries, as cancer registries compiling incidence and mortality data have not been established. The authors acknowledge that the variability in quality observed in the analysis of this data highlights the difficulties of conducting epidemiological research across countries and continents; it is a limitation of this analysis. This might be expected for developing countries in which the health care infrastructure remains underdeveloped but is surprising for countries with well-established cancer registries.

\section{Incidence}

Our study demonstrates an increase in testicular cancer incidence was seen in almost all areas assessed; of note, developed countries demonstrated a greater annual increase in testicular cancer incidence compared to the developing countries studied (1980-2002). Thus annual percent changes for overall testicular cancer incidence rates significantly increased in the European countries Sweden 2.4\%, (2.2; 2.6); UK 2.9\%, (2.2; 3.6); Spain 5.0\%, $(1.7 ; 8.4)$, Australia $3.0 \%,(2.2 ; 3.7)$, and China $3.5 \%$, $(1.9 ; 5.1)$, whereas India had the lowest overall incidence rate, with a slight decrease of $1.7 \%,(-2.5 ;-0.8)$. The geographical and temporal variability in the incidence globally may be closely associated to the changing migration patterns of populations during these time periods. This may indicate that populations either share genetic characteristics or that there are environmental factors influencing incidence. ${ }^{8}$ 
One of the main theories which may explain these changes is the birth cohort pattern. Both geographic variations and temporal changes are linked to this pattern, wherein an individual's testicular cancer risk is a result of the era in which he was born. This is also relevant for migrating populations, as first generation immigrants develop a risk of testicular cancer that mirrors the risk in their home countries rather than risks comparable to the indigenous population in their new countries; in particular, they showed a higher risk if they migrated from a high-risk area such as Denmark, and a declining risk if from low-risk countries such as Iran. ${ }^{13}$ Second-generation immigrants demonstrate an additional increase which is thought to be environmental in origin. It is assumed that both populations share a common risk factor of prenatal origin. ${ }^{13,14}$

It has previously been estimated that $25 \%$ of germ cell tumors susceptibility is attributed to genetic effects. ${ }^{15}$ Men with a family history of germ cell tumors have a 4- to 10-fold increased risk of developing testicular cancer. ${ }^{16}$ This genetic risk may be linked to the specific genes such as KITLG (c-KIT ligand) and the mitogen-activated protein (MAP) kinase pathway inhibitor SPRY4 (protein sprouty homolog 4), ${ }^{17,18}$ as well as gene-encoding estrogen receptors ESR1, ESR2, and the luteinizing hormone/ choriogonadotropin receptor (LHCGR). ${ }^{19}$ Polymorphisms in 17- $\beta$ hydroxydehydrogenase- $4,{ }^{20,21}$ the ESR2 gene (encoding estrogen receptor beta $[\mathrm{ER} \beta]$ ), ${ }^{22}$ and finally the increased transactivation of the androgen receptor gene $A R$, are also associated with a testicular cancer risk. ${ }^{23}$ Recently, evidence for an epigenetic role has also been suggested in testicular cancer. ${ }^{18}$

The influence of environmental factors on testicular cancer incidence may interfere with tumorigenesis at a number of points. In a study of 33,364 germ cell tumors from a variety of sites (gonadal, central nervous system, ovary) different age-incidence patterns presenting in different peak ages was exhibited. ${ }^{24}$ This suggests a common initiation of tumorigenesis in embryonic/fetal life, with variable rates of tumor progression as a result of subsequent environmental events. ${ }^{24}$ Environmental factors such as serum estrogen levels ${ }^{25}$ have been examined for their effect on gonadal development during fetal life. High levels are associated with "testicular dysgenesis syndrome", a combination of poor semen quality, testis cancer, undescended testis, and hypospadias. ${ }^{26}$ Furthermore, many other factors collectively known as the environmental endocrine disrupters (eg, polychlorinated biphenyls, organochlorines, nonionizing radiation, agricultural work, and tobacco) have been correlated with an increased risk of testicular cancer. They are thought to interfere with multiple hormonal pathways, thus resulting in impaired differentiation of germ cells in the fetal period and subsequent malignant transformation. ${ }^{27,28}$

As of yet it is not possible to implicate any specific genetic or environmental factors in the recent incidence increases in developed countries observed in our and others' registry analysis. It is also difficult to explain the observation of a declining incidence in India. One explanation could be a strong environmental factor which may have emerged as a result of increasing Westernization in recent years. ${ }^{2}$ Alternatively this may be an artefactual effect due to data quality. It will be important in future to secure high quality cancer registry data across all regions globally; however, at present definitive conclusions on these observations cannot be reached.

\section{Mortality}

In our study a decline in mortality was observed in almost all regions; this decline was more pronounced among the European and Oceanic countries, with the greatest changes observed in Sweden $-4.2 \%,(-4.8 ;-3.6)$ and China $-4.9 \%$, $(-6.5 ;-3.3)$. No decrease in mortality was observed in Colombia and Poland, whilst no data were available for India.

Our findings are consistent with previous reports of the global decrease in mortality rates in recent years. ${ }^{8,29}$ In particular, Rosen et al reported the highest mortality rates in Central America (0.7\%), Central and Eastern Europe (0.6\%), and Western Asia (0.6\%). ${ }^{6}$ These findings correlate with our observations in Poland and Colombia.

No data were available assessing mortality rates in African populations, although testicular cancer incidence rates are known to be low and treatment outcomes often poor in African countries. These increasing trends in mortality in countries lacking well-established health care systems often occur as a result of late diagnosis and delayed referral and treatment. ${ }^{30}$ Developed countries with specialized centers have pioneered a multidisciplinary approach to cancer care, collaborating improvements in tumor staging, systemic treatment, and surgery. ${ }^{8}$ In an effort to improve treatment, the introduction of multidisciplinary care, well-defined surveillance protocols, and dedicated surgical services are essential. $^{31}$

Given that high cure rates are achieved with current treatment regimens, efforts have been directed towards decreasing toxicity in order to minimize acute and late treatment effects. The new strategy of reducing the treatment burden 
by risk stratification has led to the use of fewer cycles of chemotherapy and the implementation of active surveillance strategies. ${ }^{32}$ The role of active surveillance has not been assessed in randomized trials, but it appears that almost all recurrences can be successfully treated with chemotherapy or radiotherapy making this a safe and desirable approach. ${ }^{33,34}$

Risk stratification using serum tumor marker levels (STMs) and tumor staging helps identify which patients are most likely to relapse and leads to personalized treatment strategies based on individual risk assessments. ${ }^{35}$

These tumor markers ( $\alpha$-fetoprotein [AFP], $\beta$-human chorionic gonadotropin [hCG], and lactate dehydrogenase $[\mathrm{LDH}])$ are of most value in the metastatic setting and often for non-seminomatous rather than seminomatous germ cell tumors. They can also facilitate early detection of relapse as part of active surveillance protocols.$^{36}$ Recent studies using expression profiling have identified genes which may be associated with the presence of metastasis. The expression of the dopamine receptor D1 (DRD1) and 'family with sequence similarity 71' (member F2 [FAM71F2]) genes were associated with the presence of metastasis in a tested cohort of stage 1 and metastatic seminoma cases. ${ }^{36}$ In nonseminomatous germ cell tumors chromosome $\mathrm{Y}$ deletions were associated with the presence of nodal metastasis in retroperitoneal lymph node dissections (RPLND). ${ }^{37}$ In addition to tumor staging, a recent study assessed the prognostic significance of age, socioeconomic status (SES), and race on 10-year testicular cancer-specific mortality in 27,948 men diagnosed with seminoma or non-seminoma. Increased mortality was observed in men aged over 40 years, while non-white, lower SES men with non-seminomatous tumors displayed a significantly increased testicular cancer-specific mortality. ${ }^{38}$ At present, despite the investigation of a number of prognostic factors, none have been extensively validated and most remain experimental.

The high cure rates in testicular cancer and subsequent long-term survival of patients requires consideration of the late effects of treatment administered. These largely center on the increased risk of cardiovascular disease and second malignancies. With regards to cardiovascular disease, a study of 990 men treated for testicular cancer with cisplatin, bleomycin, and etoposide (BEP) chemotherapy alone had a 5.7-fold higher risk (95\% confidence interval [CI], 1.9-17.1-fold) of coronary artery disease compared with surgery alone, and a 3.1-fold higher risk ( $95 \%$ CI, 1.2-7.7-fold) of myocardial infarction compared with male controls. ${ }^{39}$ As these data emerge, it is important to educate both patients and clinicians on the long-term cardiovascular risks of treatment for testicular cancer and include them in the informed consent process. In addition, advice on lifestyle modifications and regular cardiovascular risk factor assessment are required as part of survivorship programs to minimize cardiovascular morbidity and mortality in this population.

In an international population-based survey of 40,576 testicular cancer survivors, patients who were diagnosed with seminomas or non-seminomatous tumors at the age of 35 years experienced cumulative risks of solid second malignancies of $36 \%$ and $31 \%$, respectively by the age of 75 years. ${ }^{40}$ These solid tumors were diverse in subtype and included mesotheliomas, esophageal, lung, colon, bladder, pancreas, and stomach cancers. Their occurrence is assumed to be a direct effect of the chemo- and or radiotherapy treatment administered, although it remains unknown what factors confer susceptibility to second malignancy in individual patients. Since the incidence and time of onset of these effects differ between patients, there may be a genetic predisposition to long-term toxicities or even the persistence of a pluripotent cancer stem cell. ${ }^{41}$

\section{Conclusion}

Testicular cancer, including tumors of germ-cell origin, remains a rare tumor type. Its incidence continues to increase in most Caucasian populations within the developed world, where it is the most commonly diagnosed malignancy in young men. Well- developed health care systems in these countries now offer multidisciplinary approaches which achieve high cure rates. This is demonstrated by an observable reduction in mortality for these patients. Current efforts focus on individualizing cancer care and minimizing late treatment effects, as well as the identification and modification of genetic and environmental risk factors for testicular cancer occurrence. In order to accurately study the changes in incidence and outcomes of testicular cancer and all tumor types, availability of high quality cancer registry data is required. This study emphasizes that this is not currently available globally and remains to be achieved in some developing countries.

\section{Acknowledgments}

This research was supported by the Experimental Cancer Medicine Centre at King's College London and by the National Institute for Health Research (NIHR) Biomedical Research Centre, based at Guy's and St Thomas' National Health Service (NHS) Foundation Trust and King's College London and as well as Cancer Research UK. The views expressed are those of the authors and not necessarily those of the funding bodies. 


\section{Disclosure}

The authors report no conflicts of interest in this work.

\section{References}

1. Purdue MP, Devesa SS, Sigurdson AJ, McGlynn KA. International patterns and trends in testis cancer incidence. Int J Cancer. 2005;115(5): $822-827$.

2. Chia VM, Quraishi SM, Devesa SS, Purdue MP, Cook MB, McGlynn KA. International trends in the incidence of testicular cancer, 1973-2002. Cancer Epidemiol Biomarkers Prev. 2010;19(5):1151-1159.

3. Ferlay J, Shin HR, Bray F, Forman D, Mathers C and Parkin DM. GLOBOCAN 2008, cancer incidence and mortality worldwide: IARC CancerBase No.10. Lyon, France: International Agency for Research on Cancer. 2010 v2.0. Available from: http://globocan.iarc.fr. Accessed February 1, 2013.

4. Richiardi L, Bellocco R, Adami HO, et al. Testicular cancer incidence in eight northern European countries: secular and recent trends. Cancer Epidemiol Biomarkers Prev. 2004;13(12):2157-2166.

5. Horwich A, Shipley J, Huddart R. Testicular germ-cell cancer. Lancet. 2006;367(9512):754-765.

6. Rosen A, Jayram G, Drazer M, Eggener SE. Global trends in testicular cancer incidence and mortality. Eur Urol. 2011;60(2):374-379.

7. Wanderås $\mathrm{EH}$, Tretli S, Fosså SD. Trends in incidence of testicular cancer in Norway 1955-1992. Eur J Cancer. 1995;31A(12):2044-2048.

8. Bray F, Richiardi L, Ekbom A, Pukkala E, Cuninkova M, Møller H. Trends in testicular cancer incidence and mortality in 22 European countries: continuing increases in incidence and declines in mortality. Int J Cancer. 2006;118(12):3099-3111.

9. Trama A, Mallone S, Nicolai N, et al; RARECARE Working Group. Burden of testicular, paratesticular and extragonadal germ cell tumours in Europe. Eur J Cancer. 2012;48(2):159-169.

10. WHO Mortality Database [database on the Internet]. Geneva, Switzerland: World Health Organization. Available from: http://www.who.int/healthinfo/ statistics/mortality/en/index.html. Accessed November 16, 2012.

11. Ferlay J, Parkin DM, Curado MP, Bray F, Edwards B, Shin HR, Forman D. Cancer Incidence in Five Continents, Volumes I to IX: IARC CancerBase No. 9. Lyon, France: International Agency for Research on Cancer. 2010. Available from: http://ci5.iarc.fr. Accessed November 16, 2012.

12. Kim HJ, Fay FM, Feuer EJ, Midthune DN. Permutation tests for joinpoint regression with applications to cancer rates. Stat Med. 2000;19(3): $335-351$.

13. Beiki O, Granath F, Allebeck P, Akre O, Moradi T. Subtype-specific risk of testicular tumors among immigrants and their descendants in Sweden, 1960 to 2007. Cancer Epidemiol Biomarkers Prev. 2010;19(4): 1053-1065.

14. Hemminki K, Mousavi SM, Brandt A, Ji J, Sundquist J. Histologyspecific risks in testicular cancer in immigrants to Sweden. Endocr Relat Cancer. 2010;17(2):329-334.

15. Turnbull C, Rahman N. Genome-wide association studies provide new insights into the genetic basis of testicular germ-cell tumour. Int J Androl. 2011;34(4 Pt 2):e86-e96; discussion e96-e97.

16. Greene MH, Kratz CP, Mai PL, et al. Familial testicular germ cell tumors in adults: 2010 summary of genetic risk factors and clinical phenotype. Endocr Relat Cancer. 2010;17(2):R109-R121.

17. GuY, Runyan C, Shoemaker A, Surani A, Wylie C. Steel factor controls primordial germ cell survival and motility from the time of their specification in the allantois, and provides a continuous niche throughout their migration. Development. 2009;136(8):1295-1303.

18. Vega A, Baptissart M, Caira F, Brugnon F, Lobaccaro JM, Volle DH. Epigenetic: a molecular link between testicular cancer and environmental exposures. Front Endocrinol (Lausanne). 2012;3:150.

19. Brokken LJ, Lundberg-Giwercman Y, Rajpert De-Meyts E, et al. Association of polymorphisms in genes encoding hormone receptors ESR1, ESR2 and LHCGR with the risk and clinical features of testicular germ cell cancer. Mol Cell Endocrinol. 2012;351(2):279-285.
20. Chia VM, Li Y, Quraishi SM, et al. Effect modification of endocrine disruptors and testicular germ cell tumour risk by hormone-metabolizing genes. Int J Androl. 2010;33(4):588-596.

21. Ferlin A, Ganz F, Pengo M, Selice R, Frigo AC, Foresta C. Association of testicular germ cell tumor with polymorphisms in estrogen receptor and steroid metabolism genes. Endocr Relat Cancer. 2010;17(1):17-25.

22. Kristiansen W, Andreassen KE, Karlsson R, et al. Gene variations in sex hormone pathways and the risk of testicular germ cell tumour: a caseparent triad study in a Norwegian-Swedish population. Hum Reprod. 2012;27(5):1525-1535.

23. Davis-Dao CA, Siegmund KD, Vandenberg DJ, et al. Heterogenous effect of androgen receptor CAG tract length on testicular germ cell tumor risk: shorter repeats associated with seminoma but not other histologic types. Carcinogenesis. 2011;32(8):1238-1243.

24. Arora RS, Alston RD, Eden TO, Geraci M, Birch JM. Comparative incidence patterns and trends of gonadal and extragonadal germ cell tumors in England, 1979 to 2003. Cancer. 2012;118(17):4290-4297.

25. Sharpe RM, Skakkebaek NE. Are oestrogens involved in falling sperm counts and disorders of the male reproductive tract? Lancet. 1993;341(8857):1392-1395.

26. Skakkebaek NE, Rajpert-De Meyts E, Main KM. Testicular dysgenesis syndrome: an increasingly common developmental disorder with environmental aspects. Hum Reprod. 2001;16(5):972-978.

27. Meeks JJ, Sheinfeld J, Eggener SE. Environmental toxicology of testicular cancer. Urol Oncol. 2012;30(2):212-215.

28. McGlynn KA, Trabert B. Adolescent and adult risk factors for testicular cancer. Nat Rev Urol. 2012;9(6):339-349.

29. Levi F, La Vecchia C, Boyle P, Lucchini F, Negri E. Western and eastern European trends in testicular cancer mortality. Lancet. 2001;357(9271): 1853-1854.

30. Ugwumba FO, Aghaji AE. Testicular cancer: Management challenges in an African developing country. SAfr Med J. 2010;100(7):452-455.

31. Vlayen J, Vrijens F, Devriese S, Beirens K, Van Eycken E, Stordeur S. Quality indicators for testicular cancer: a population-based study. Eur J Cancer. 2012;48(8):1133-1140.

32. Singhera M, Lees K, Huddart R, Horwich A. Minimizing toxicity in early-stage testicular cancer treatment. Expert Rev Anticancer Ther. 2012;12(2):185-193.

33. Aparicio J, Maroto P, del Muro XG, et al. Risk-adapted treatment in clinical stage I testicular seminoma: the third Spanish Germ Cell Cancer Group study. J Clin Oncol. 2011;29(35):4677-4681.

34. Thompson PI, Nixon J, Harvey VJ. Disease relapse in patients with stage I nonseminomatous germ cell tumor of the testis on active surveillance. J Clin Oncol. 1988;6(10):1597-1603.

35. Keskin S, Ekenel M, Başaran M, Bavbek S. Predictive value of marker half-life in relapsed and nonrelapsed nonseminomatous germ cell testicular tumor patients undergoing chemotherapy. Am J Clin Oncol. 2012;35(4):369-372.

36. RufCG, Linbecker M, Port M, et al. Predicting metastasized seminoma using gene expression. BJU Int. 2012;110(2 Pt 2):E14-E20.

37. Mohamed GH, Gelfond JA, Nicolas MM, et al. Genomic characterization of testis cancer: association of alterations with outcome of clinical stage 1 mixed germ cell nonseminomatous germ cell tumor of the testis. Urology. 2012;80(2):485.e1-485.e5.

38. Fosså SD, Cvancarova M, Chen L, et al. Adverse prognostic factors for testicular cancer-specific survival: a population-based study of 27,948 patients. J Clin Oncol. 2011;29(8):963-970.

39. Haugnes HS, Wethal T, Aass N, et al. Cardiovascular risk factors and morbidity in long-term survivors of testicular cancer: a 20-year followup study. J Clin Oncol. 2010;28(30):4649-4657.

40. Travis LB, Fosså SD, Schonfeld SJ, et al. Second cancers among 40,576 testicular cancer patients: focus on long-term survivors. J Natl Cancer Inst. 2005;97(18):1354-1365.

41. Travis LB, Beard C, Allan JM, et al. Testicular cancer survivorship: research strategies and recommendations. J Natl Cancer Inst. 2010;102(15):1114-1130. 
Clinical Epidemiology

\section{Publish your work in this journal}

Clinical Epidemiology is an international, peer-reviewed, open access journal focusing on disease and drug epidemiology, identification of risk factors and screening procedures to develop optimal preventative initiatives and programs. Specific topics include: diagnosis, prognosis, treatment, screening, prevention, risk factor modification, systematic

Submit your manuscript here: http://www.dovepress.com/clinical-epidemiology-journal

reviews, risk \& safety of medical interventions, epidemiology \& biostatical methods, evaluation of guidelines, translational medicine, health policies \& economic evaluations. The manuscript management system is completely online and includes a very quick and fair peer-review system, which is all easy to use. 